BMJ Open

Sport \&

Exercise

Medicine

\title{
Susceptibility to exertional heat illness and hospitalisation risk in UK military personnel
}

\author{
Michael J Stacey, ${ }^{1,2}$ lain T Parsons, ${ }^{2}$ David R Woods, ${ }^{2,3}$ Peter N Taylor, ${ }^{4}$ \\ David Ross, ${ }^{5}$ Stephen J Brett ${ }^{1,6}$
}

To cite: Stacey MJ, Parsons IT, Woods DR, et al. Susceptibility to exertional heat illness and

hospitalisation risk in UK military personnel. BMJ Open Sport Exerc Med 2015;1:000055. doi:10.1136/ bmjsem-2015-000055

- Prepublication history and additional material is availabl. To view please visit the journal (http://dx.doi.org/10. 1136/bmjsem-2015-000055).

Accepted 11 September 2015

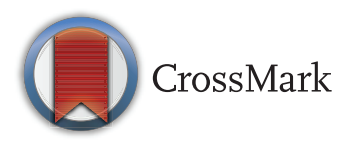

For numbered affiliations see end of article.

Correspondence to Dr Michael J Stacey; m.stacey13@imperial.ac.uk

\section{ABSTRACT}

Background: Susceptibility to exertional heat illness $(E H I)$ is considered multifactorial in nature. The aims of this study were to (1) review traditional susceptibility factors identified in cases of EHI and (2) determine how they are related to risk of hospitalisation.

Methods: Review of an electronic database of EHI reported in the British Army between 1 September 2007 and 31 December 2014. Cases were categorised by demographic, situational and susceptibility variables. Univariate and multivariate logistic regression was performed for the OR for hospitalisation by risk factor.

Results: 361 reports were included in the analysis. $33.5 \%$ of cases occurred in hot climates, $34.6 \%$ in temperate climates during summer months and $31.9 \%$ in temperate climates outside of summer months. Traditional susceptibility factors were reported in 193 but entirely absent from 168 cases. 137 cases (38.0\%) were admitted to hospital. Adjusted OR for hospitalisation was lower for recruits (OR $0.42,95 \% \mathrm{Cl}$ 0.18 to $0.99, p<0.05)$ and for personnel wearing occlusive dress (OR $0.56,95 \% \mathrm{Cl} 0.34$ to 0.93 , $\mathrm{p}<0.05)$ or unacclimatised to heat (OR $0.31,95 \% \mathrm{Cl}$ 0.15 to $0.66, p<0.01$ ).

Conclusions: The global, year-round threat of $\mathrm{EH}$ is highlighted. Absence of susceptibility factors in nearly half of reports highlights the challenge of identifying EHI-prone individuals. Paradoxical association of traditional susceptibility factors with reduced hospitalisation risk may reflect the contemporary contexts in which severe EHI occurs. These findings also suggest a need for better evidence to inform guidelines that aim to prevent severe $\mathrm{EHI}$ concurrent to reducing overall morbidity.

\section{INTRODUCTION}

In occupational and recreational settings, strenuous physical exertion presents a risk of incapacitation, illness and occasional death from exertional heat illness (EHI). Although EHI may be predisposed by external factors, such as climate or clothing characteristics, its root cause is internal heat produced during muscular exercise. ${ }^{1}{ }^{2}$ Studies in civilian

\section{What are the new findings}

- Although hospitalisation tended to be associated with hotter climates, nearly a third of all exertional heat illness (EHI) was sustained by UK military personnel during non-summer months in temperate climates.

- The traditional susceptibility factors that were reported most frequently in contemporary cases of EHI were dehydration, febrile/infectious illness, sleep deprivation and lack of acclimatisation.

- Surprisingly, the OR for hospitalisation was reduced in unacclimatised personnel and was not increased by intercurrent illness or sleep deprivation.

- OR for hospitalisation from EHI was lower among recruits than in trained personnel. Hospitalisation $\mathrm{OR}$ was also lower, not higher, when occlusive dress was worn rather than vented.

athletes and military personnel have reported an incidence that may exceed 20 episodes per 10000 exposures in hot environments, ${ }^{3-5}$ as well as highlighting factors associated with increased susceptibility. ${ }^{6-8}$ These traditional risk factors form the basis of personalised preventive guidance, ${ }^{6}{ }^{9-11}$ though the pathophysiological entities encompassed by the term EHI are heterogeneous $^{2}{ }^{12}$ and susceptibility to severe illness could differ within and between exposed populations. $^{13} 14$

Exertional heat stroke (EHS) is the most severe form of EHI, whereby excessive body heat results in a syndrome of impaired consciousness and systemic inflammatory response. ${ }^{15} 16$ The mechanisms by which a participant passes from exertional hyperthermia to a state of collapse characterised by catastrophic disturbances of the nervous, cardiovascular and haematological systems are incompletely understood. In recent years, the US military has observed a paradoxical escalation in the incidence of EHS on a 
background of falling total reports of EHI. ${ }^{14} 17$ Lifethreatening EHS often occurs in young adults and, in common with other forms of EHI, may be considered more preventable than treatable. ${ }^{16}$ This helps to explain why heat-implicated deaths among civilian athletes and military personnel have the capacity to attract widespread attention and critical reaction to the circumstances in which they occurred. ${ }^{19} 20$

In the modern era, the UK military has operated a code of practice to reduce morbidity from EHI, combining prospective control measures with retrospective investigation of EHI incidents. Physician reporting has formed one component of this process, and an electronic database of EHI episodes occurring under the jurisdiction of the British Army has been maintained since 2007. Using this database, the aims of this study were to (1) review the circumstances surrounding episodes of EHI, including the presence of identifiable susceptibility factors and (2) assess how these factors relate to severity of clinical outcome, using hospitalisation as a surrogate for severe EHI.

\section{METHODS}

A case record review was conducted for EHI incidents that occurred between 1 September 2007 and 31 December 2014. Cases were UK military personnel serving under British Army command, who were diagnosed with heat illness by physicians employed by the UK Ministry of Defence (MoD). Cases of 'heat illness' were defined in MoD guidance to physicians as 'those individuals who become incapacitated as a result of a rise in core body temperature'. Physicians were required to report confirmed cases using a standard MoD Heat Illness Medical Reporting form (see online supplementary figure) that was completed by hand and sent by post or facsimile transmission to the Army Medical Directorate Health Unit. Details were entered prospectively into an electronic database, maintained in accordance with the UK Data Protection Act. The Army Caldicott Guardian provided authority to analyse the database, which was anonymised beforehand by removal of patient names and military service numbers.

Inclusion of demographic information in the analysis was limited to occupational seniority (recruits, junior ranks and senior ranks including officers); and age (dichotomised as $<30$, $\geq 30$ years). Further situational data extracted from the database included the prevailing climate from which the report had arisen (hot or temperate) and, for temperate climates, whether the incident had occurred in summer or non-summer months (Northern Hemisphere Summer months being defined as the three warmest months of June, July and August). Cases of EHI were isolated from episodes where heat illness had occurred without reference to strenuous physical exertion. Activities were categorised as grouppaced when the speed of performance was simultaneously imposed across a unit of individuals, or self-paced when greater personal freedom was allowed in varying the tempo of activity.

Data were also summarised by variables that have been reported to influence EHI susceptibility (table 1): the state of dress worn during activity (standard uniform and other 'occlusive' states of dress that would reduce heat dissipation vs relatively vented clothing such as shorts and singlet or trousers and T-shirt); physical fitness, as indicated by recent evidence of passing standard military fitness tests; physician-assessed hydration state and acclimatisation status; physician-elicited sleep balance, evidence of febrile or infectious illness and previous history of EHI. ${ }^{6-8}$ Clinical outcomes were categorised as ambulatory care, with or without attendance

\begin{tabular}{|c|c|}
\hline Domain & Categories \\
\hline \multicolumn{2}{|c|}{ Demographic and situational factors } \\
\hline Occupational seniority & Recruits*; junior ranks; senior ranks and officers \\
\hline Age & $<30 ;>30$ years \\
\hline Prevailing climate & Hot climate*; temperate climate-summer months*; temperate climate-other months \\
\hline Pacing of activity & Group-paced or self-paced \\
\hline Clothing ensemble worn & $\begin{array}{l}\text { Occlusive* (standard uniform }+/- \text { additional insulation, such as body armour);vented } \\
\text { (reduced insulation relative to standard uniform, with exposure of bare skin below the } \\
\text { elbow) }\end{array}$ \\
\hline \multicolumn{2}{|l|}{ Individual susceptibility factors } \\
\hline Physical fitness level & Physically fit§, or unfit* \\
\hline Heat acclimatisation status & Acclimatised or unacclimatised ${ }^{*}$ \\
\hline Hydration state & Dehydrated ${ }^{\star}$ or euhydrated/overhydrated \\
\hline Medical history & Positive for $\mathrm{EHI}^{\star}$ or no history of $\mathrm{EHI}$ \\
\hline Sleep balance & Sleep deprived* or rested adequately \\
\hline $\begin{array}{l}\text { Febrile or infectious } \\
\text { (intercurrent) illness }\end{array}$ & Present ${ }^{\star}$ or absent \\
\hline
\end{tabular}


at a medical facility (including cases discharged from secondary care following attendance at emergency departments and those supervised overnight in military primary care centres) or hospitalisation for inpatient management by an internal or intensive care medicine service.

Logistic regression was undertaken to investigate the odds of individuals requiring hospitalisation for EHI for each risk factor, with co-adjustment for potential confounding. Wald tests were used to determine $p$ values for each resulting OR. Assessment of SEs was undertaken to check for multicollinearity. Confirmatory bootstrap analyses were undertaken using 1000 repetitions and occupational seniority and age as strata. The study was underpowered to assess for interactions. All data analyses were performed using STATA V.12.1 (STATACORP, College Station, Texas, USA).

\section{RESULTS}

\section{Total EHI cases}

A total of $389 \mathrm{EHI}$ cases were identified from 88 months of reporting (4.4 cases/month). Details were incomplete for $28 \mathrm{EHI}$ incidents (7.2\% of identified cases) and these reports were removed from further consideration. Demographic and situational data from the remaining 361 cases are displayed at figure 1. Physician-reported susceptibility factors are displayed by frequency at figure 2.

One hundred and twenty-one EHI cases $(33.5 \%$ of series) were reported from hot climates, such as Iraq, Brunei and Cyprus. In the remainder of the series, the overwhelming majority occurred in the UK (236 cases or $65.4 \%$ of series), with just over half of these temperate climate cases arising during the summer months (125 cases or $34.6 \%)$. One hundred and fifteen cases $(31.9 \%$ of total) were reported from temperate climates in nonsummer months, including a small number of cases from Germany.

Traditional risk factors for EHI were reported for 193 casualties, but were entirely absent from the other 168 . Multiple risk factors were identified in 110 cases, most often as a combination of dehydration with intercurrent illness (57 cases) and/or sleep deprivation (31 cases). Lack of heat acclimatisation was identified in 63 cases of EHI, of whom 47 were affected in a region of prevailing hot climate, versus 16 in temperate climates (11 in summer months, 5 during other months).

\section{EHI outcomes, including hospitalisation}

Of 361 cases of EHI, 277 attended hospital and 137 were admitted for inpatient management (38.0\% of series). This hospitalisation rate was similar to that among all 389 cases identified in the original database (36.8\%). Cases requiring hospitalisation originated more commonly from temperate climates in summer months (35.6\% of total hospitalisations) than from hot climates
$(32.6 \%)$ or temperate climates in non-summer months $(31.9 \%)$.

Traditional risk factors for EHI were absent in 74 hospitalised cases $(54.0 \%)$ and were identified as singleton factors in a further 30 cases $(22.2 \%)$. Multiple risk factors were identified in the remaining 33 cases, for whom dehydration in combination with intercurrent illness (18 cases) and/or sleep deprivation (11 cases) was reported most commonly. Lack of heat acclimatisation was identified in only 13/137 hospitalised cases, with 10 of these casualties arising in hot climates and 3 in the temperate UK climate (1 case in summer, 2 during other months).

Adjusted results of logistic regression for hospitalisation risk are presented in table 2. Of the traditional risk factors for EHI, none were associated with statistically increased OR for hospitalisation, whereas individuals from three 'higher risk' categories were at significantly reduced risk of hospitalisation: recruits, personnel wearing occlusive dress and casualties who had been judged unacclimatised to heat by treating physicians. Bootstrap analysis confirmed these statistically significant associations (see online supplementary table).

\section{DISCUSSION}

This study demonstrates that EHI is frequently diagnosed in temperate climates outside of summer months and that recruits, personnel wearing occlusive dress and those who are unacclimatised to heat are at reduced risk of hospitalisation. The enduring threat posed by EHI and the novel association of traditional risk factors with reduced, not increased, OR for hospitalisation raise important questions about how best to facilitate physical performance and limit harm from severe EHI.

The need to inform heat stress management of military activities with epidemiological research applies equally to sport. ${ }^{9} 1113$ Calls for evidence and guidelines that apply more specifically to individual sports and athletic events are valid, ${ }^{11} 21$ but are limited by the relative rarity of EHS. Lessons from settings and populations in which severe EHI occurs more commonly, such as the military, may offer valuable insights into the principal concern about heat stress: namely, the risk of developing dangerous levels of hyperthermia. ${ }^{13}$

\section{Demographic factors}

Historically, military recruits have appeared to be at increased risk of fatal EHI. ${ }^{20} 2223$ In American football, heat-attributed deaths have affected younger, high school-age and college-age players disproportionately. ${ }^{24}$ Recent reporting indicates that British Army recruits have higher rates of EHI than more experienced personnel. ${ }^{25}$ Yet while trainees in the US armed forces continue to suffer an excess of $\mathrm{EHS}^{17}$ and heat-related deaths take a persistent toll on young football players, ${ }^{24}$ the present study found that British Army recruits were at reduced, not increased, risk of hospitalisation from EHI. 
Figure 1 Demographic and situational information for all 361 exertional heat illness cases (left) and 137 hospitalised cases (right), displayed by (A) occupational category, (B) age, (C) pacing of activity and (D) clothing ensemble worn.
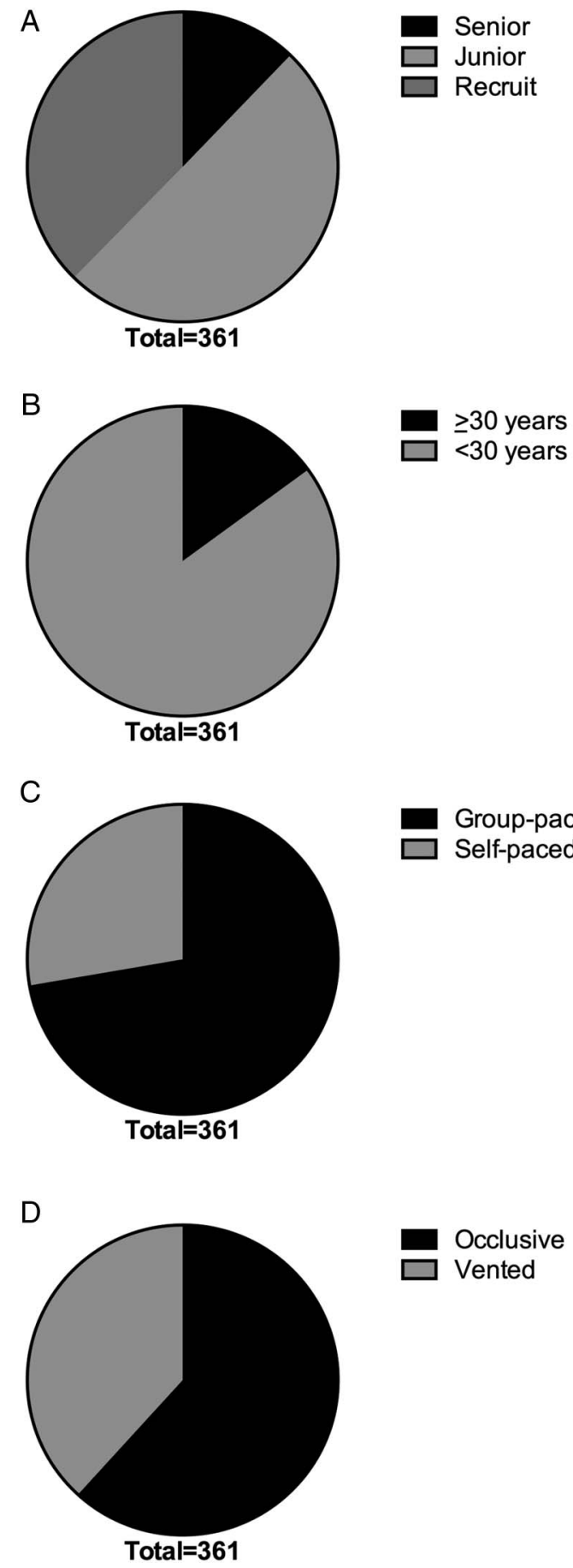

$\geq 30$ years $<30$ years

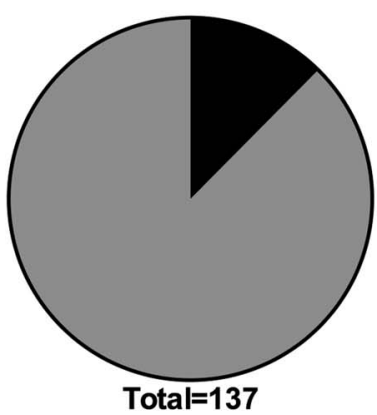

Group-paced Self-paced
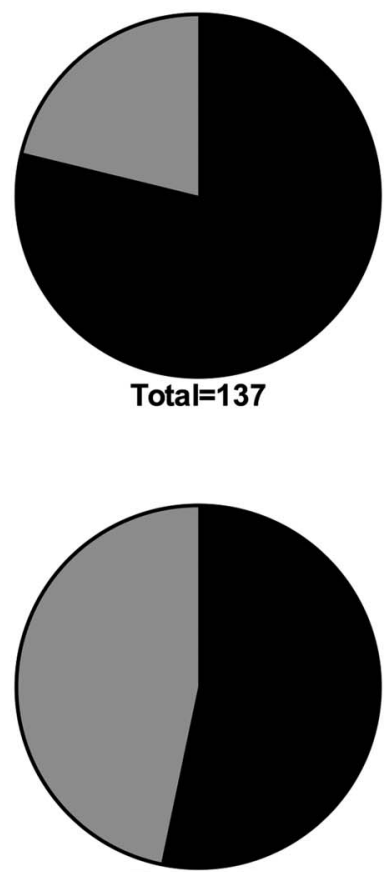

Total=137
Evolving or established episodes of EHI may have been more likely to be mitigated or aborted among the recruit population in this study, perhaps due to early recognition and appropriate treatment. Army training establishments have been the focus of repeated MoD efforts to reduce the incidence and severity of EHI, ${ }^{26-28}$ and this may have resulted in the lower hospitalisation rate of recruits compared with trained personnel. Management of cases arising outside of recruit training centres could also have varied according to the skills, experience and resources of medical responders in deployable units. In some of the more austere settings in which trained UK personnel operate, access to treatment facilities may be restricted and this could have influenced a decision to treat and reassess at the scene, versus evacuating to higher echelons of care.

\section{Situational factors}

In common with military personnel, American football players engage in strenuous activities while wearing uniforms. Additional insulating garments and protective equipment add to the occlusive nature of uniformed 
Figure 2 Traditional risk factors identified in (A) 361 exertional heat illness cases (all clinical outcomes) and (B) 137 hospitalised cases.
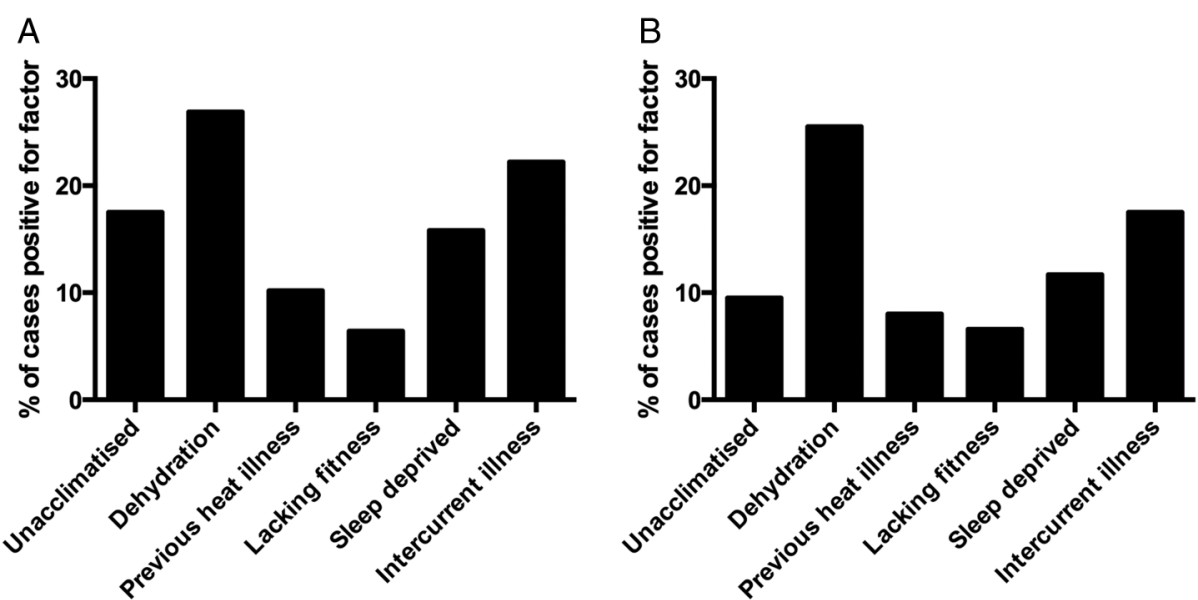

dress. Important practical, psychological and adaptive benefits may accrue from training in the clothing ensembles that will be worn during competition and combat. These benefits must be weighed against additional heat production from load carriage and reduced heat dissipation in layered or impermeable clothing, from which a state of uncompensable heat stress-characterised by rising core temperature and heat storage-may arise. ${ }^{6}$

Most uniformed military activities approach or cross into states of thermal uncompensability. ${ }^{29}$ The OR for hospitalisation associated with occlusive dress was not increased in the present study, however, but rather was reduced by almost half relative to vented dress. This may simply reflect a relationship between the intensity of exercise and the risk of severe EHI, with MoD guidance advocating the selection of lower intensities when training is conducted with additional insulation and loads. These findings also accord with common military guidelines that target a lower core temperature limit during uncompensable exposures, by requiring commanders to incorporate frequent breaks during planned training activities. $^{29}$

Group-paced activities (eg, marching and collective carriage of heavy loads while running) accounted for

Table 2 Results of logistic regression for hospitalisation outcome according to traditional susceptibility factors for exertional heat illness (EHI) among 361 personnel over 88 months of reporting

\begin{tabular}{|c|c|c|c|c|}
\hline Susceptibility variable & OR $(95 \% \mathrm{Cl})$ & p Value ${ }^{*}$ & OR $(95 \% \mathrm{Cl}) \S$ & p Value*§ \\
\hline Senior ranks and officers & 1 [Reference] & - & 1 [Reference] & - \\
\hline Junior ranks & $1.12(0.57$ to 2.20$)$ & 0.735 & $0.97(0.44$ to 2.15$)$ & 0.939 \\
\hline Recruits & $0.73(0.36$ to 1.49$)$ & 0.392 & $0.42(0.18$ to 0.99$)$ & 0.047 \\
\hline Age $<30$ years & 1 [Reference] & - & 1 [Reference] & - \\
\hline Age $>30$ years & $0.74(0.40$ to 1.37$)$ & 0.331 & $0.60(0.29$ to 1.23$)$ & 0.164 \\
\hline Temperate climate, non-summer months & 1 [Reference] & - & 1 [Reference] & - \\
\hline Temperate climate, summer months§ & $1.04(0.62$ to 1.76$)$ & 0.872 & 1.09 (0.62 to 1.91$)$ & 0.752 \\
\hline Hot climate§ & 0.96 (0.56 to 1.62$)$ & 0.870 & $1.38(0.67$ to 2.80$)$ & 0.381 \\
\hline Self-paced & 1 [Reference] & - & 1 [Reference] & - \\
\hline Group-paced & $1.67(1.02$ to 2.75$)$ & 0.042 & $1.66(0.86$ to 3.17$)$ & 0.128 \\
\hline Vented clothing & 1 [Reference] & - & 1 [Reference] & - \\
\hline Occlusive clothing & 0.60 (0.39 to 0.92$)$ & 0.020 & 0.56 (0.34 to 0.93$)$ & 0.025 \\
\hline Physically fit & 1 [Reference] & - & 1 [Reference] & - \\
\hline Lack of documented fitness & $0.92(0.39$ to 2.20$)$ & 0.859 & $0.93(0.30$ to 2.38$)$ & 0.879 \\
\hline Acclimatised to heat & 1 [Reference] & - & 1 [Reference] & - \\
\hline Unacclimatised & $0.38(0.20$ to 0.72$)$ & 0.003 & $0.31(0.15$ to 0.66$)$ & 0.002 \\
\hline Euhydated/overhydrated & 1 [Reference] & - & 1 [Reference] & - \\
\hline Dehydrated & $0.93(0.57$ to 1.50$)$ & 0.755 & $1.47(0.76$ to 2.82$)$ & 0.249 \\
\hline No history of EHI & 1 [Reference] & - & 1 [Reference] & - \\
\hline Previous EHI & $0.68(0.33$ to 1.43$)$ & 0.311 & $0.72(0.33$ to 1.58$)$ & 0.412 \\
\hline Rested adequately & 1 [Reference] & - & 1 [Reference] & - \\
\hline Sleep deprived & $0.61(0.33$ to 1.14$)$ & 0.115 & 0.76 (0.37 to 1.56$)$ & 0.454 \\
\hline No identifiable illness & 1 [Reference] & - & 1 [Reference] & - \\
\hline Febrile or infectious (intercurrent) illness & 0.66 (0.38 to 1.12$)$ & 0.123 & $0.52(0.26$ to 1.05$)$ & 0.068 \\
\hline
\end{tabular}

${ }^{*}$ Calculated using the Wald test.

$\S$ Adjusted for occupational seniority, age, prevailing climate, pacing of activity, clothing ensemble worn, physical fitness level, heat acclimatisation status, hydration state, history of $\mathrm{EHI}$, sleep balance and presence/absence of intercurrent illness. 
$70 \%$ of total EHI cases and $78.5 \%$ of hospitalisations in this study. Self-paced activities were characterised by greater dispersal of individuals and included foot patrols, solo marches, competitive runs and recreational activities such as multisport events. High levels of motivation, extreme performance goals and factors that potentially impair thermal perception-such as hyponatraemia from overdrinking ${ }^{30}$-could arise in either pacing category. The distinction may be less relevant to EHI susceptibility, therefore, though a trend towards increased hospitalisation from group pacing was apparent and may have attained statistical significance in the multivariate analysis if the study was larger.

\section{Traditional risk factors for EHI}

In a large series of EHI casualties from the US Army, dehydration at point of incapacitation was reported in $17 \%$ of cases. ${ }^{14}$ It has been highlighted that this factor was absent in the other $83 \%$ of cases ${ }^{31}$ and that substantial dehydration may arise without ill effect in successful civilian endurance runners. ${ }^{32}$ On the other hand, the British Army has practised 'breaking the march' for water intake since the time of Wellington ${ }^{33}$ and its recent experiences support this practice. After participating in a special forces selection event conducted during a heat wave in July 2013, three British Army soldiers died from the effects of heat. At inquest, inadequate provision of water was identified as contributory to the death of one soldier and was highlighted as a factor in other cases of EHI arising in the same event. ${ }^{34}$ In the present study, the increased OR for hospitalisation associated with dehydration did not attain statistical significance, but lends support to the idea that water intake may play a role in preventing severe EHI in this particular population. Where water is available ad libitum, a protective mechanism may be the pause in strenuous muscular activity-allowing body temperature to fall and reducing total heat storage-rather than maintaining or forcing hydration levels per se.

The most striking difference between traditional risk factors identified in hospitalised cases of EHI and those managed without admission to secondary care relates to acclimatisation status. Intrinsic heat production may exceed the body's capacity for dissipation at any time of year, ${ }^{1}$ and in relation to activity-specific outcomes, acclimatisation should be judged as an individual's expected tolerance for a given combination of internal and external heat. ${ }^{35} 36$ The finding that 'unacclimatised' cases of EHI were reported from temperate climates, outside of summer months, provides evidence that physicians asked the appropriate question regarding acclimatisation status: 'acclimatisation to what?' ${ }^{35}$ If this reporting practice was consistently observed, then our findings are noteworthy, though potentially controversial. Recent consensus guidelines present heat acclimatisation as 'the most important intervention one can adopt to reduce physiological strain and optimise performance', ${ }^{11}$ yet it would appear that those individuals who were considered best adapted to heat were at risk of greatest harm from its effects.

It has been shown that acclimatisation is associated with reduced incidence of syncope during exercise in the first days of heat exposure, ${ }^{37}$ but empirical evidence for a reduction in EHS is lacking. Acclimatisation was not considered protective in French military personnel deployed overseas, in whom the median time to being hospitalised as a result of EHI was 60 days from arrival..$^{88}$ Further evidence to support an increased risk of hospitalisation in association with heat acclimatisation is provided by a previous study of EHI among British Army personnel in Cyprus. While those military personnel making short (3-4 week) training visits were more likely to suffer EHI, these episodes were generally mild, whereas resident personnel were four times more likely to be affected by severe EHI requiring hospitalisation for $24 \mathrm{~h}$ or longer. ${ }^{39}$

In the present study, a minority of cases hospitalised in hot climates were unacclimatised and nearly all UK cases of EHI were judged acclimatised. These findings align with a model proposing that individuals adapted to higher relative levels of heat stress may suffer more severe forms of EHI, in association with transient reductions in heat tolerance during strenuous exertion. ${ }^{40}$ The trend towards a reduced, not increased, OR for hospitalisation in cases affected by febrile and infectious illnesses suggests that readily identifiable disease may not have been the universal trigger for this mechanism. In fact, infections associated with EHI in the literature have often been subclinical in nature, ${ }^{41-44}$ which may have allowed individuals to exercise under higher levels of heat load than if overtly unwell. The ability to perform prolonged intense exercise has itself been implicated in immune disturbances that may lead to EHS, though this may not account for cases of severe EHI arising early in the course of physical activity. ${ }^{28}$

\section{Limitations of the study}

This study was limited by incomplete or inconsistent reporting in areas of direct relevance, including the clinical parameters of body temperature, level of consciousness and circulatory sufficiency. In the absence of adequate diagnostic information to differentiate EHS from other heat-related causes of incapacitation, hospitalisation was used as a surrogate for severe EHI. The full criteria for EHS may not have been met by all hospitalised cases of EHI; it is also possible that elevated core body temperature was not the primary cause of incapacitation in some cases, who may have received a diagnosis of EHI while suffering from other exercise-related pathologies. $^{2}$

The lack of adequate denominator data on the entire populations exposed to risk of EHI also presents a real challenge and limits how far these issues can be explored. While capturing complete data from military field exercises and operations can prove difficult, ${ }^{17}{ }^{25}$ with web-based data capture now widely available, it may 
be possible to generate useful databases on exposed populations during more formal physical training. Recent efforts by several international sporting federations have been reported in response to the challenge of evaluating epidemiological outcomes from the application of existing or updated preventive guidelines during major competitions. ${ }^{11} 19214546$

\section{CONCLUSIONS}

Preventing severe EHI poses a universal challenge, which extends beyond hot climates and unacclimatised personnel. Traditional risk factors may not predict severity as they associate with overall morbidity and the use of existing guidance does not appear to protect all vulnerable individuals. It is beholden on military and civilian governing bodies to assess the impact of current risk assessment practices on ultimate clinical outcomes and to investigate novel approaches to identifying EHS susceptibility, both before and during activity. In the meantime, this study shows that individuals prone to severe EHI remain difficult to identify and highlights the need for greater vigilance, even in seemingly low-risk scenarios.

\section{Author affiliations \\ ${ }^{1}$ Section of Anaesthetics, Pain Medicine and Intensive Care, Imperial College, London, UK \\ ${ }^{2}$ Department of Military Medicine, Royal Centre for Defence Medicine, Birmingham, UK \\ ${ }^{3}$ Professor of Sport and Exercise Endocrinology, Carnegie Faculty, Leeds Beckett University, Leeds UK \\ ${ }^{4}$ Thyroid Research Group, Institute of Molecular \& Experimental Medicine, Cardiff University School of Medicine, Cardiff, UK \\ ${ }^{5}$ Parkes Professor of Preventive Medicine, Army Health Unit, Former Army Staff College, Camberley, UK \\ ${ }^{6}$ Reader in Critical Care, Centre for Perioperative Medicine and Critical Care Research, Imperial College Healthcare NHS Trust, UK}

Acknowledgements Mr Alan Tidy (S03 Health Information, Army Medical Directorate) curated the electronic database of heat illness reporting to the Army Medical Directorate Health Unit in association with DR. This research was supported by the (NIHR) Biomedical Research Centre based at Imperial College Healthcare Trust and Imperial College, London. The views expressed are those of the authors and not necessarily the NHS or the NIHR.

Contributors MJS is responsible for the overall content as guarantor.

Competing interests None declared.

Provenance and peer review Not commissioned; internally peer reviewed.

Data sharing statement This submission, including the supplementary files, comprises all data available for public release.

Open Access This is an Open Access article distributed in accordance with the Creative Commons Attribution Non Commercial (CC BY-NC 4.0) license, which permits others to distribute, remix, adapt, build upon this work noncommercially, and license their derivative works on different terms, provided the original work is properly cited and the use is non-commercial. See: http:// creativecommons.org/licenses/by-nc/4.0/

\section{REFERENCES}

1. Smith JE. Cooling methods used in the treatment of exertional heat illness. Br J Sports Med 2005;39:503-7.
2. Noakes TD. A modern classification of the exercise-related heat illnesses. J Sci Med Sport 2008;11:33-9.

3. Gosling CM, Gabbe BJ, McGivern J, et al. The incidence of heat casualties in sprint triathlon: the tale of two Melbourne race events. J Sci Med Sport 2008;11:52-7.

4. DeMartini J, Casa DJ, Belval LN, et al. Environmental conditions and the occurrence of exertional heat illnesses and exertional heat stroke at the Falmouth Road Race. J Athl Train 2014;49:478-85.

5. Mager M, Hubbard RW, Kerstein MD. Survey and analysis of the medical experience for CAX 8-80. Technical Report. Natick, MA: US Army Research Institute of Environmental Medicine, 1980.

6. Armstrong LE, Casa DJ, Millard-Stafford M, et al. American College of Sports Medicine Position Stand. Exertional heat illness during training and competition. Med Sci Sports Exerc 2007;39:556-72.

7. Minard D. Prevention of heat casualties in Marine Corps recruits. Mil Med 1961;126:261-72.

8. Shibolet $\mathrm{S}$, Coll R, Gilat T, et al. Heat-stroke: its clinical picture and mechanism in 36 cases. Q J Med 1967;36:525-47.

9. Bergeron MF, Bahr R, Bärtsch P, et al. International Olympic Committee consensus statement on thermoregulatory and altitude challenges for high-level athletes. Br J Sports Med 2012;46:770-9.

10. Lipman GS, Eifling KP, Ellis MA, et al. Wilderness Medical Society practice guidelines for the prevention and treatment of heat-related illness: 2014 update. Wilderness Environ Med 2014;25: S55-65.

11. Racinais S, Alonso JM, Coutts AJ, et al. Consensus recommendations on training and competing in the heat. Br J Sports Med 2015:49:1164-73.

12. Joslin J, Mularella J, Worthing R. Heat-related illness: time to update our lexicon. Wilderness Environ Med 2014;25:249-51.

13. Brotherhood JR. Heat stress and strain in exercise and sport. J Sci Med Sport 2008;11:6-19.

14. Carter R III, Cheuvront SN, Williams JO, et al. Epidemiology of hospitalizations and deaths from heat illness in soldiers. Med Sci Sports Exerc 2005;37:1338-44.

15. Bouchama A, Knochel JP. Heat stroke. N Engl J Med 2002;346:1978-88.

16. Leon LR, Bouchama A. Heat stroke. Compr Physiol 2015;5:611-47.

17. Armed Forces Health Surveillance Center. Update: heat injuries, active component, U.S. Armed Forces, 2014. MSMR 2015;22:17-20.

18. Leon LR, Helwig BG. Heat stroke: role of the systemic inflammatory response. J Appl Physiol 2010;109:1980-8.

19. Bergeron MF, Engebretsen L. Protecting elite athletes in extreme and challenging environments: advancing the dialogue. Br J Sports Med 2012;46:769.

20. Porter AM. The death of a British officer cadet from heat illness. Lancet 2000;355:569-71.

21. Bahr R, Reeser JC. New guidelines are needed to manage heat stress in elite sports-the Federation Internationale de Volleyball (FIVB) Heat Stress Monitoring Programme. Br J Sports Med 2012;46:805-9.

22. Cook EL. Epidemiological approach to heat trauma. Mil Med 1955; $116: 317-22$

23. Ellis FP. Prevention of heat incapacitation in the Armed Forces. Mil Med 1955;116:323-9.

24. Kucera KL, Klossner D, Colgate B, et al. Annual Survey of Football Injury Research, 1931-2014. National Center for Catastrophic Injury Research. http://nccsir.unc.edu/reports/ (accessed 02 Aug 2015)

25. Stacey MJ, Brett S, Woods D, et al. Case ascertainment of heat illness in the British Army: evidence of under-reporting from analysis of Medical and Command notifications, 2009-2013. J R Army Med Corps 2015. doi:10.1136/jramc-2014-000384.

26. Burgess JE. Analysis of $Y$ listings and medical discharges of officer Cadets at RMAS from January 1994 to May 1997, with actions to prevent injuries. J R Army Med Corps 1998;144:152-5.

27. Cordell RF. Training injuries-how clinicians can help commanders avoid them. J R Army Med Corps 2004;150:244-51.

28. Stacey M, Woods D, Ross D, et al. Heat illness in military populations: asking the right questions for research. J R Army Med Corps 2014;160:121-4.

29. Task Group HFM 187. Management of heat and cold stress guidance to NATO medical personnel. NATO Science and Technology Organisation. https://www.cso.nato.int/pubs/rdp.asp? RDP=RTO-TR-HFM-187 (accessed 02 Aug 2015).

30. Nolte HW, Hew-Butler T, Noakes TD, et al. Exercise-associated hyponatremic encephalopathy and exertional heatstroke in a soldier: high rates of fluid intake during exercise caused rather than prevented a fatal outcome. Phys Sportsmed 2015;43:93-8.

31. Cotter JD, Thornton SN, Lee JK, et al. Are we being drowned in hydration advice? Thirsty for more? Extrem Physiol Med 2014;3:18. 
32. Beis LY, Wright-Whyte M, Fudge B, et al. Drinking behaviors of elite male runners during marathon competition. Clin J Sport Med 2012;22:254-61.

33. Craufurd A. General Craufurd and his light division. Uckfield, East Sussex: Naval and Military Press, 2006:76-7.

34. http://www.southwalesargus.co.uk/news/gwentnews/13417922 Neglect_played_a_part_in_deaths_of_soldiers_in_Brecon Beacons_SAS_march/ (accessed 02 Aug 2015).

35. Knochel JP. Environmental heat illness. An eclectic review. Arch Intern Med 1974;133:841-64.

36. Taylor NA. Human heat adaptation. Compr Physiol 2014;4:325-65.

37. Bean WB, Eichna LW. Performance in relation to environmental temperature. Reactions of normal young men to simulated desert environment. Fed Proc 1943;2:144-58.

38. Abriat A, Brosset $\mathrm{C}$, Brégigeon $\mathrm{M}$, et al. Report of 182 cases of exertional heatstroke in the French Armed Forces. Mil Med 2014;179:309-14.

39. Bricknell MC. Heat illness in the army in Cyprus. Occup Med 1996;46:304-12.
40. Lim CL, Mackinnon LT. The roles of exercise-induced immune system disturbances in the pathology of heat stroke: the dual pathway model of heat stroke. Sports Med 2006;36:39-64.

41. Roberts WO. Exertional heat stroke during a cool weather marathon: a case study. Med Sci Sports Exerc 2006;38:1197-202.

42. Carter R III, Cheuvront SN, Sawka MN. A case report of idiosyncratic hyperthermia and review of U.S. Army heat stroke hospitalizations. J Sport Rehabil 2007;16:238-43.

43. Rav-Acha M, Hadad E, Epstein $\mathrm{Y}$, et al. Fatal exertional heat stroke: a case series. Am J Med Sci 2004;328:84-7.

44. Sonna LA, Wenger CB, Flinn S, et al. Exertional heat injury and gene expression changes: a DNA microarray analysis study. J Appl Physiol 2004;96:1943-53.

45. Grantham J, Cheung SS, Connes P, et al. Current knowledge on playing football in hot environments. Scand J Med Sci Sports 2010;20(Suppl 3):161-7.

46. Mountjoy M, Alonso JM, Bergeron MF, et al. Hyperthermic related challenges in aquatics, athletics, football, tennis and triathlon. Br J Sports Med 2012;46:800-4. 